\title{
THE CO-CULTURE OF KERATINOCYTES AND FIBROBLASTS ON A MULTI-LAYERED POLYESTER NANOFIBROUS MEMBRANE ENRICHED WITH PLATELET LYSATE
}

\author{
${ }^{1}$ Andreu BLANQUER, ${ }^{1}$ Elena FILOVA, ${ }^{2}$ Vera JENCOVA, ${ }^{1}$ Antonin BROZ, ${ }^{2}$ Eva KUZELOVA \\ KOSTAKOVA, ${ }^{2}$ Maxim LISNENKO, ${ }^{3}$ Renata PROCHAZKOVA, ${ }^{1}$ Lucie BACAKOVA \\ ${ }^{1}$ Institute of Physiology of the Czech Academy of Sciences, Prague, Czech Republic, EU, \\ andreu.blanquerierez@fgu.cas.cz \\ ${ }^{2}$ Technical University of Liberec, Faculty of Sciences, Liberec, Czech Republic, EU, vera.jencova@tul.cz \\ ${ }^{3}$ Regional Hospital in Liberec, Liberec, Czech Republic, EU, renata.prochazkova@nemlib.cz
}

https://doi.org/10.37904/nanocon.2021.4364

\begin{abstract}
The prevalence of chronic wounds is increasing due to the population ageing and specific illnesses like diabetes mellitus and vascular diseases. Nanofibrous membranes fabricated using synthetic polymers are promising materials to enhance skin wound healing. PCL and PVA membranes are being studied to be used as scaffolds for skin tissue engineering and hydrogels for controlled drug delivery, respectively. The present study considers the development of a multi-layered membrane made of PCL and PVA loaded with platelet lysate (PL). PCL nanofibers allowed cell adhesion and growth, whereas PVA acted as a hydrogel that releases the bioactive compounds of platelet lysate. The cytocompatibility of the membranes containing PL and without it was demonstrated on two cell types involved in wound healing, i.e. keratinocytes and fibroblasts. Both cell types were able to adhere and proliferate on the membranes. In addition, the membrane containing PL enhanced the proliferation of fibroblasts. A co-culture study was also performed by seeding each cell type on one side of the membrane. The cells were co-cultured for 7 days and the results showed that PL increased the proliferation of cells achieving a monolayer of keratinocytes or fibroblasts on each side of the membrane. Thus, the beneficial effect of PCL-PVA+PL membranes on monocultures and co-cultures of skin cells was demonstrated, and these membranes can be considered potential scaffolds for treatment of chronic wounds.
\end{abstract}

Keywords: Skin wound healing, electrospun nanofibers, platelet lysate, keratinocytes, fibroblasts

\section{INTRODUCTION}

Wound healing is a physiological process that involves multiple cell types, growth factors, cytokines and other metabolites and ions [1]. Among the cell types present in skin wound healing, keratinocytes and fibroblasts are two of the most important ones. Keratinocytes are the main cell type in epidermis, whereas fibroblasts are the main cell type in dermis. Both cell types proliferate and migrate to the wound site during the proliferation phase of wound healing. However, in chronic wounds, the proliferation of skin-resident cells is significantly reduced $[2,3]$.

The increasing number of chronic wounds is becoming burdensome in terms of both human health and socioeconomic consequences [4]. The prevalence of chronic wounds increases along with vascular diseases, diabetes mellitus and other systemic factors like advanced age. Indeed, many adult patients suffering from type 2 diabetes mellitus develop ulcers, including the diabetic foot ulcer [5]. It is therefore necessary to develop new wound dressings or skin scaffolds to improve wound healing.

Synthetic biocompatible polymers are widely used in tissue engineering. Specifically, nanofibrous membranes fabricated by electrospinning are considered promising materials for the regeneration of damaged skin. One of the advantages of nanofibrous membranes is that they mimic the fibrous component of the natural 
extracellular matrix, as well as they protect the wound against microbes. Moreover, these nanofibrous membranes are able to support cell adhesion, migration, growth and differentiation [6]. Among synthetic polymers, polycaprolactone $(P C L)$ is widely used due to its high degree of solubility in a variety of solvents and its tunable mechanical properties. Poly(vinyl alcohol) (PVA) is another type of synthetic polymer that can be used to develop nanofibrous scaffolds. PVA is a highly hydrophilic and chemically resistant polymer, and allows the incorporation of bioactive substances which are soluble in water.

In the present study, we prepared a multi-layered nanofibrous membrane of PCL and PVA, and we incorporated platelet lysate (PL) into PVA. PCL nanofibers allowed cell adhesion and growth, whereas PVA acted as a hydrogel releasing bioactive compounds. The multilayer membrane was fabricated as a scaffold and a drug-releasing membrane with an interesting potential for skin wound healing. The cytocompatibility of the membrane and the effect of PL was analyzed using keratinocytes and fibroblasts on day 1 and 7 after cell seeding. Moreover, keratinocytes and fibroblasts were seeded on both sides of the membrane and co-cultured for 7 days.

\section{METHODS}

\subsection{Platelet lysate preparation}

A platelet concentrate was prepared via the centrifuge separation of platelets from human buffy coats obtained from 4 patients. The experimental procedure was previously described by Blanquer et al. [7]. Briefly, the buffy coats from the 4 patients were mixed and centrifuged to separate the platelet concentrate from the red blood cells and leukocytes. The final platelet concentration was determined to be in the range $600 \times 10^{9}$ to $850 \times 10^{9}$ platelets/L. The PL were then prepared using the freeze-thaw method. The supernatant, i.e. PL, was stored at $-80^{\circ} \mathrm{C}$.

\subsection{Nanofibrous membranes fabrication and characterization}

A multi-layer membrane of poly( $\varepsilon$-caprolactone) (PCL) and poly(vinyl alcohol) (PVA) was fabricated by the direct current needleless electrospinning technique (Nanospider 1WS500U, Elmarco, Liberec, Czech Republic). The electrospinning solution for PCL contained 16\% (w/w) PCL (Mn 45,000 g/mol) in chloroform/ethanol solution (8:2). For the PVA electrospinning solution, PVA with a molecular weight of 125,000 and degree of hydrolysis of $98 \%$ was electrospun from a $10 \%(\mathrm{w} / \mathrm{w})$ polymer solution in a water/ethanol solution (9:1). PVA containing PL and without PL were prepared. The PVA+PL was prepared from PVA by adding $10 \% \mathrm{w} / \mathrm{w}$ of $\mathrm{PL}$ in the spinning solution immediately before electrospinning. The morphology of nanofibers was analysed by scanning electron microscopy and the diameter of the fibres was evaluated from at least 130 measurements using NIS Elements software (Nikon).

\subsection{Cell culture}

Human HaCaT keratinocytes (CLS Cell Lines Services) were cultured in Dulbecco's Modified Eagle's Medium (DMEM; ThermoFisher Scientific) with 10\% fetal bovine serum (FBS; ThermoFisher Scientific) under standard conditions $\left(37^{\circ} \mathrm{C}\right.$ and $5 \% \mathrm{CO}_{2}$ ). Normal human dermal fibroblasts from neonatal foreskin (NHDF; Lonza) were cultured until passage 4 in DMEM with $10 \%$ FBS under standard conditions.

For monocultures of HaCaT cells and NHDF, membranes were cut into pieces of one $\mathrm{cm}^{2}$ area and placed on a 24-well plate. Both cell types were seeded at a density of 20,000 cells per well and cultured over time. For co-culture experiments, a density of 20,000 NHDF cells per well was seeded on one side of the membranes, and after 1 hour required for cell adhesion, the membranes were placed upside down in a fresh cell culture plate. Then, HaCaT cells were seeded at a density of 50,000 cells per well on the opposite side of the membranes and cultured for 7 days in DMEM with 10\%FBS. Cell culture medium was replaced after 4 days. 


\subsection{Metabolic activity/Cell proliferation}

The metabolic activity, which is considered to be related to the cell number, was determined by CellTiter $96 \AA$ AQueous One Solution Cell Proliferation Assay (MTS, Promega Corporation). The membranes with cells were transferred to fresh 24-well plates for the MTS analysis. The samples were incubated with $500 \mu \mathrm{l}$ of phenol red-free DMEM supplemented with $10 \%$ FBS and $100 \mu$ of MTS for $1 \mathrm{~h}$. The absorbance was measured using a VersaMax ELISA Microplate Reader spectrophotometer (Molecular Devices Corporation) at a wavelength of $490 \mathrm{~nm}$, and normalized per well.

\subsection{Cytoskeleton visualization}

Following the MTS assay, the cells were rinsed with phosphate-buffered saline (PBS) and fixed with $4 \%$ paraformaldehyde in PBS for $30 \mathrm{~min}$. The initial cell adhesion and morphology were analyzed via the staining of the cells with phalloidin after 1 day in culture. In addition, cells grown for 7 days were stained with phalloidin. The samples were incubated with Atto 488-conjugated phalloidin (1:500; Sigma-Aldrich), i.e. a dye for actin cytoskeleton, and Hoechst 33258 ( $5 \mu \mathrm{g} / \mathrm{ml}$ in PBS, Sigma-Aldrich), i.e. a dye for the cell nuclei, for $20 \mathrm{~min}$ at room temperature (RT). Images of the adherent cells were captured under an IX-50 microscope equipped with a DP 70 digital camera (both from Olympus) and a spinning disk confocal microscope equipped with a Zyla 4.2 PLUS sCMOS camera (Andor).

\section{RESULTS AND DISCUSSION}

\subsection{Characterization of the nanofibrous membranes}

The measurements of the fiber diameters revealed that electrospun PCL-PVA membranes contained fibers with a wide range of diameters (approx. from $140 \mathrm{~nm}$ to $1.2 \mu \mathrm{m}$ ). The mean diameter was $340 \pm 170 \mathrm{~nm}$. Similar fiber diameters were observed for PCL-PVA+PL membranes, the mean diameter being $320 \pm 210 \mathrm{~nm}$.

\subsection{Cell adhesion and cytoskeleton organization}
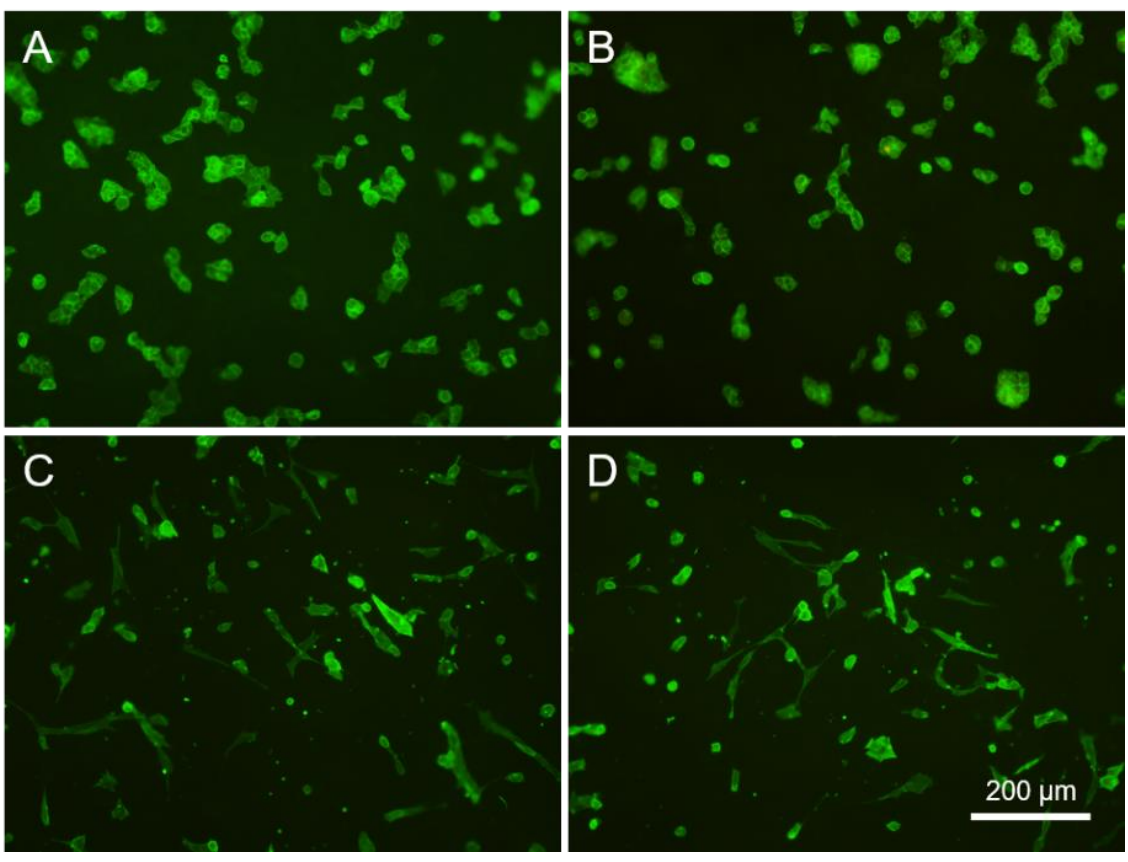

Figure $1 \mathrm{HaCaT}$ cells $(A, B)$ and $\operatorname{NHDF}(C, D)$ that adhered to PCL-PVA+PL $(A, C)$ and PCL-PVA $(B, D)$ nanofibrous membranes on day 1 after seeding. Images of the cells stained with phalloidin-Atto488 (green);

Olympus IX50 microscope equipped with DP70 digital camera. 
The cell adhesion and cytoskeleton organization of the cells grew on the membranes were evaluated after 24 hours in culture. The results indicated that $\mathrm{HaCaT}$ cells were able to adhere on both samples, with and without $\mathrm{PL}$. The cells showed a rounded shape and created small island-like clusters in certain regions, which is the normal morphology and behavior of keratinocytes after $24 \mathrm{~h}$ of culturing (Figure 1). The fibroblasts were also able to adhere and spread on nanofibrous membranes. The cell morphology of fibroblasts was polygonal or spindle-shape, although few cells presented a rounded shape (Figure 1). No differences between samples were observed for fibroblasts adhesion and morphology after day 1 in culture. The initial adhesion of cells on the nanofibrous membranes is a necessary step for anchorage-dependent cells, including keratinocytes and fibroblasts. PCL is more hydrophobic than other synthetic polymers, and therefore it has been considered less supportive for cell adhesion [8]. This disadvantage has been mitigated by electrospinning of PCL with other polymers or bioactive additives. The results concerning the initial adhesion and morphology of cells indicated that the developed multi-layered nanofibrous membranes provided a suitable growth support for the basic skin cells types, i.e. keratinocytes and fibroblasts .

\subsection{Proliferation of monocultured HaCaT cells and NHDF}

The metabolic activity of the HaCaT cells and NHDF cultured on the membranes for 1 and 7 was quantified. The cells were found to proliferate on both membranes tested without any signs of cytotoxic or cytostatic effects (Figure 2). On day 1 following seeding, the metabolic activity of $\mathrm{HaCaT}$ cells and NHDF did not show significant differences between PCL-PVA and PCL-PVA+PL nanofibrous membranes. On day 7, similar metabolic activity was observed for $\mathrm{HaCaT}$ cells. However, the metabolic activity of NHDF cultured for 7 days was observed to be higher on membranes containing PL than on membranes without PL. Previously, we demonstrated that PVA nanomats containing PL enhanced the metabolic activity of 3T3 fibroblasts [9]. PL contains a mixture of cytokines, growth factors and other bioactive molecules, which can influence the behavior of keratinocytes and fibroblasts. Indeed, PL has been demonstrated to accelerate the proliferation of fibroblasts, keratinocytes and endothelial cells [10,11].

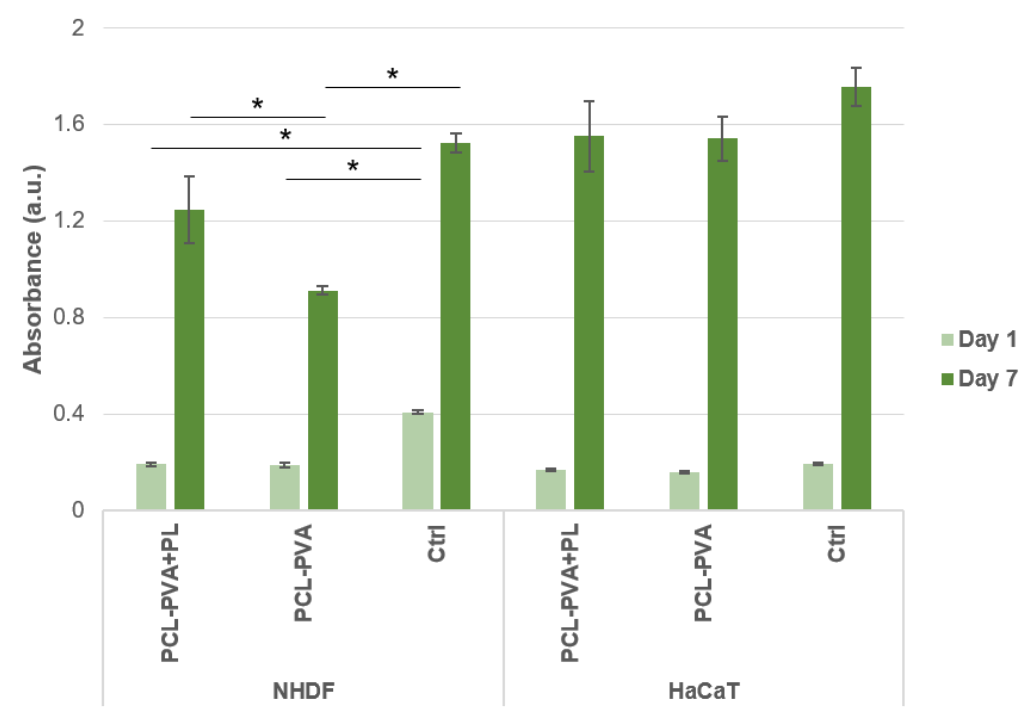

Figure 2 Metabolic activity of the NHDF and HaCaT cells that grew on the PCL-PVA+PL and PCL-PVA nanofibrous membranes in monoculture for 1 and 7 days. The asterisks indicate significant differences between samples for each cell type and time point $(p<0.05)$.

\subsection{HaCaT cells and NHDF co-cultured on membranes}

The nanofibrous membranes allowed a co-culture of keratinocytes and fibroblasts on both sides of the membrane. The membrane was used a barrier to segregate each cell type. In addition, it was used as an 
artificial basement membrane, which constitutes the anchorage of the epithelium and the connective tissue in skin tissue [12]. Under in vitro conditions, the membranes created a physical barrier to avoid the contact between the two cell types and the potential overgrowth of one of them. However, the nanofibrous membranes allowed the molecular exchange by sharing the cell culture medium and all the bioactive compounds secreted by cells.

The morphology and cytoskeleton organization of the cells co-cultured on the membranes were analyzed by actin stress fiber staining on day 7 after cell seeding (Figure 3). Images showed that HaCaT cells were able to proliferate on both PCL-PVA and PCL-PVA+PL membranes and the morphology was also similar on both membranes. The fibroblasts proliferated on membranes and oriented in parallel. Both cell types created a monolayer on membranes containing PL, but several void spaces were observed on samples without PL. The results were in agreement with the previous results obtained on monocultures. The PL enhanced the proliferation of fibroblasts in monocultures, and it also enhanced the proliferation of keratinocytes in cocultures. We hypothesize that the presence of fibroblasts could influence positively the proliferation of keratinocytes.
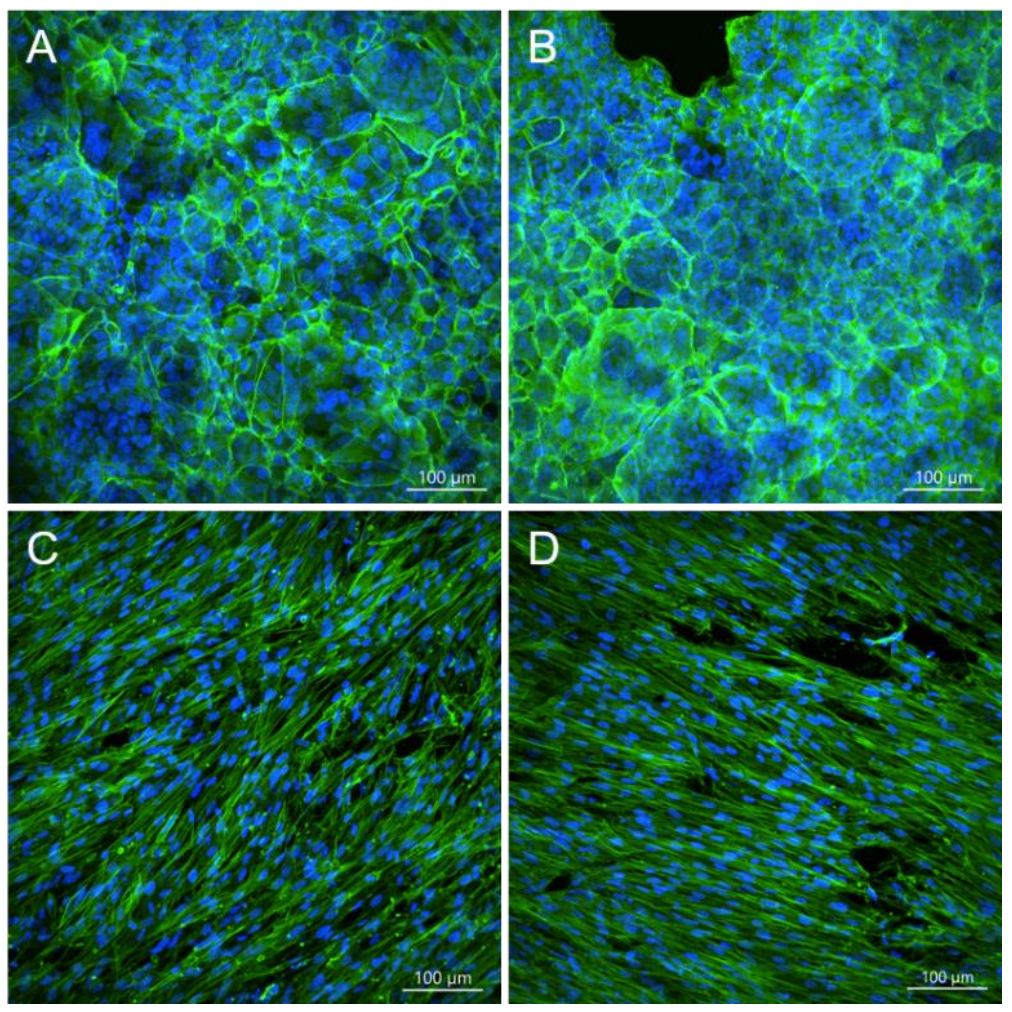

Figure $3 \mathrm{HaCaT}$ cells $(\mathrm{A}, \mathrm{B})$ and NHDF (C, D) co-cultured on PCL-PVA+PL (A, C) and PCL-PVA (B, D) nanofibrous membranes for 7 after cell seeding. Images of the cells stained with phalloidin-Atto488 (green) and Hoechst (blue); spinning disk confocal microscope equipped with a Zyla 4.2 PLUS sCMOS camera.

\section{CONCLUSION}

The PCL-PVA and PCL-PVA+PL membranes allowed the adhesion and proliferation of keratinocytes and fibroblasts without exerting any cytotoxic effect. The presence of PL in PVA enhanced the proliferation of fibroblasts when cultured in monoculture. The growth of keratinocytes and fibroblasts in co-culture was also enhanced on membranes containing PL. The multi-layered membrane demonstrate to be safe for co-culture of the two skin cell types. Thus, nanofibrous membrane loaded with PL have the potential to be used as bioactive scaffolds in chronic wound treatment. 


\section{ACKNOWLEDGEMENTS}

\section{This project has received funding from the European Union's Horizon 2020 research and innovation programme (grant agreement No. 101003407-ELECTROSKIN) and the Czech Health Research Council, Ministry of Health of the Czech Republic (project No. NV18-01-00332).}

\section{REFERENCES}

[1] SANON, S.; HART, D.A.; TREDGET, E.E. Molecular and Cellular Biology of Wound Healing and Skin Regeneration. Elsevier Inc., 2016. ISBN 9780128016541.

[2] YAN, J.; TIE, G.; WANG, S.; TUTTO, A.; DEMARCO, N.; KHAIR, L.; FAZZIO, T.G.; MESSINA, L.M. Diabetes impairs wound healing by Dnmt1-dependent dysregulation of hematopoietic stem cells differentiation towards macrophages. Nat. Commun. [online]. 2018, vol. 9, Available from: https://doi.org/10.1038/s41467-017-02425-z.

[3] HOLL, J.; KOWALEWSKI, C.; ZIMEK, Z.; FIEDOR, P.; KAMINSKI, A.; OLDAK, T.; MONIUSZKO, M.; ELJASZEWICZ, A. Chronic Diabetic Wounds and Their Treatment with Skin Substitutes. Cells. [online]. 2021, vol. 10, pp. 1-21, Available from: https://doi.org/10.3390/cells10030655.

[4] SEN, C.K.; GORDILLO, G.M.; ROY, S.; KIRSNER, R.; LAMBERT, L.; HUNT, T.K.; GOTTRUP, F.; GURTNER, G.C.; LONGAKER, M.T. Human skin wounds: A major and snowballing threat to public health and the economy: PERSPECTIVE ARTICLE. Wound Repair Regen. [online]. 2009, vol. 17, pp. 763-771. Available from: https://doi.org/10.1111/j.1524-475X.2009.00543.x.

[5] FRYKBERG, R.G.; BANKS, J. Challenges in the Treatment of Chronic Wounds. Adv. Wound Care [online]. 2015, vol. 4, pp. 560-582. Available from: https://doi.org/10.1089/wound.2015.0635.

[6] BACAKOVA, L.; ZIKMUNDOVA, M.; PAJOROVA, J.; BROZ, A.; FILOVA, E.; BLANQUER, A.; MATEJKA, R.; STEPANOVSKA, J.; MIKES, P.; JENCOVA, V.; et al. Nanofibrous Scaffolds for Skin Tissue Engineering and Wound Healing Based on Synthetic Polymers. In: Applications of Nanobiotechnology; IntechOpen, 2020.

[7] BLANQUER, A.; MUSILKOVA, J.; FILOVA, E.; TABORSKA, J.; BRYNDA, E.; RIEDEL, T.; KLAPSTOVA, A.; JENCOVA, V.; MULLEROVA, J.; KOSTAKOVA, E.K.; et al. The Effect of a Polyester Nanofibrous Membrane with a Fibrin-Platelet Lysate Coating on Keratinocytes and Endothelial Cells in a Co-Culture System. Nanomaterials [online]. 2021, vol. 11, p. 457. Available from: https://doi.org/10.3390/nano11020457.

[8] SCHUHLADEN, K.; RAGHU, S.N.V.; LIVERANI, L.; NEŠČÁKOVÁ, Z.; BOCCACCINI, A.R. Production of a novel poly( $\varepsilon$-caprolactone)-methylcellulose electrospun wound dressing by incorporating bioactive glass and Manuka honey. J. Biomed. Mater. Res. - Part B Appl. Biomater. [online]. 2020, vol. 1-13. Available from: https://doi.org/10.1002/jbm.b.34690.

[9] FILOVA, E.; BLANQUER, A.; KNITLOVA, J.; PLENCNER, M.; JENCOVA, V.; KOPRIVOVA, B.; LISNENKO, M.; KOSTAKOVA, E.K.; PROCHAZKOVA, R.; BACAKOVA, L. The Effect of the Controlled Release of Platelet Lysate from PVA Nanomats on Keratinocytes. Endothelial Cells and Fibroblasts. [online]. 2021. Available from: https://doi.org/10.3390/nano 11040995.

[10] TENCI, M.; ROSSI, S.; BONFERONI, M.C.; SANDRI, G.; BOSELLI, C.; DI LORENZO, A.; DAGLIA, M.; ICARO CORNAGLIA, A.; GIOGLIO, L.; PEROTTI, C.; et al. Particulate systems based on pectin/chitosan association for the delivery of manuka honey components and platelet lysate in chronic skin ulcers. Int. J. Pharm. [online]. 2016, vol. 509, pp. 59-70. Available from: https://doi.org/10.1016/j.ijpharm.2016.05.035.

[11] BAIK, S.Y.; LIM, Y.A.; KANG, S.J.; AHN, S.H.; LEE, W.G.; KIM, C.H. Effects of platelet lysate preparations on the proliferation of hacat cells. Ann. Lab. Med. [online]. 2014, vol. 34, pp. 43-50. Available from: https://doi.org/10.3343/alm.2014.34.1.43.

[12] LIN, H.Y.; CHEN, S.H.; CHANG, S.H.; HUANG, S.T. Tri-layered chitosan scaffold as a potential skin substitute. J. Biomater. Sci. Polym. Ed. [online]. 2015, vol. 26, pp. 855-867. Available from: https://doi.org/10.1080/09205063.2015.1061350. 